\title{
Erratum to: Exploitation of technological variability among wild non-Saccharomyces yeasts to select mixed starters for the production of low alcohol wines
}

\author{
G. Alberico, A. Pietrafesa, A. Capece, R. Pietrafesa, G. Siesto, and P. Romano
}

Università degli Studi della Basilicata, Scuola di Scienze Agrarie, Forestali, Alimentari ed Ambientali, Viale dell'Ateneo Lucano 10, 85100 Potenza (PZ)

Original article:

BIO Web of Conferences 15, 02031 (2019), DOI: 10.1051/bioconf/20191502031

The list of authors should be replaced by the following text:

G. Alberico, A. Pietrafesa, A. Capece, R. Pietrafesa, G. Siesto, and P. Romano 